\title{
Exploring barriers to climate change adaptation in the Swiss tourism sector
}

\author{
Cecilia Matasci • Sylvia Kruse • Nico Barawid • \\ Philippe Thalmann
}

Received: 29 November 2012 / Accepted: 22 April 2013 / Published online: 12 June 2013

C The Author(s) 2013. This article is published with open access at Springerlink.com

\begin{abstract}
Increasingly, various sectors are affected by climate change and need to find ways to adapt with much public guidance and support. This paper examines the adaptation process of a sector that started it some time ago - Swiss Alpine tourism. It identifies barriers that may be relevant for all sectors, all along the successive phases of the adaptation process. It additionally identifies the barriers which are most important and how these can be overcome. In order to do this we use an online survey directed to Swiss tourism stakeholders. Our results indicate that both economic and social feasibility barriers are important impediments to the adjustment process, whereas the acceptability among inhabitants and the willingness to act of stakeholders appear less critical. These barriers can be overcome and adaptation facilitated with more and especially better information about the regional consequences of climate change and feasible adaptation measures, by some top-down leadership and coordination, and by providing financial support.
\end{abstract}

Keywords Adaptation - Adaptation strategy - Alps - Barriers to adaptation - Climate change · Mountain regions $\cdot$ Switzerland $\cdot$ Tourism $\cdot$ Willingness to adapt

\section{Introduction}

Adaptation is necessary if we are to manage the risks posed by unavoidable climate change (Adger and Barnett 2009; Smith et al. 2011). Considerable research on adaptation has been

C. Matasci $(\bowtie) \cdot$ P. Thalmann

Research Group on the Economics and Management of the Environment (REME), School of Architecture, Civil and Environmental Engineering (ENAC), École Polytechnique Fédérale de Lausanne (EPFL),

Station 16, 1015 Lausanne, Switzerland

e-mail: cecilia.matasci@gmail.com

S. Kruse

Research Group Regional Economics and Development, Research Unit Economics and Social Sciences, Swiss Federal Institute for Forest, Snow and Landscape Research (WSL), Birmensdorf, Switzerland

N. Barawid

Blavatnik School of Government, University of Oxford, Oxford, UK 
conducted, yet the majority of studies do not report on adaptation actions but on vulnerability assessments, planned adaptation actions or intentions to adapt (Berrang-Ford et al. 2011), even though most adaptation studies do note the existence of barriers to adaption action (Ford et al. 2011). Thus, the study of barriers to adaptation and of ways to overcome them is gaining critical interest in adaptation research (Adger et al. 2009; Jantarasami et al. 2010; Jones 2010; Moser and Ekstrom 2010; Ekstrom et al. 2011; Gifford 2011; Huang et al. 2011). Over the last decade, different conceptual frameworks and methodologies were developed with a view to conceptualizing those barriers and finding ways to overcome them. In an early conceptual paper, Smit and Pilifosova (2001) identified a list of determinants of adaptive capacity. These act as barriers when not sufficiently available. They grouped them into six classes: i) economic resources, ii) technology, iii) information and skills, iv) infrastructure, v) institutions and vi) equity. The Fourth Assessment Report of the United Nations Intergovernmental Panel on Climate Change (IPCC) remained rather general about barriers to adaptation, defining them as "obstacles to reaching a potential that can be overcome by a policy, program, or measure" (IPCC 2007). Based on a literature review, Moser and Ekstrom (2010) showed that a broad range of barriers can arise in the different phases of the adaptation process, from understanding the adaptation problem to planning appropriate adaptation measures until finally managing the planned measures and monitoring the outcomes. They come to the conclusion that policies, programs and measures designed to overcome barriers to adaptation need to be highly context specific, i.e. to consider the respective system of interest, the spatial context and actors involved for each phase of the adaptation process. Consequently, in a broad range of case study research, barriers have been analyzed empirically by focusing on selected regions and economic sectors (e.g. Grothmann and Patt 2005; Lorenzoni et al. 2007; Amundsen et al. 2010; Jantarasami et al. 2010; Nielsen and Reenberg 2010; Storbjörk 2010; Dupuis and Knoepfel 2011; Jones and Boyd 2011; Measham et al. 2011; Lata and Nunn 2012).

Tourism is one of the largest global economic sectors and at the same time strongly exposed to climate change both now and in the future (Hall and Higham 2005; Gössling and Hall 2006; IPCC 2007; Scott et al. 2011, 2012). Scott et al. (2011) have identified the climate as a key factor influencing the tourism systems through complex direct and indirect channels. Daily weather, seasonality, inter-annual variability and extreme events, all influenced by climate change, have an influence on tourist and source markets (e.g. travel motivation and destination), tourism operators (e.g. tourism offers, marketing) and tourism destinations (e.g. seasonal demand) (Scott et al. 2011, 2012). Surprisingly though, climate change adaptation research for the tourism sector is far less developed than in other economic sectors (Scott and Becken 2010), even though research on climate change mitigation in the tourism sector has been conducted since the mid-1980s with substantial growth in the last 15 years (Hall and Higham 2005; Gössling and Hall 2006; Scott and Becken 2010; Scott et al. 2012). Of 1,741 adaptation studies conducted between 2006 and 2009 and reviewed by Ford et al. (2011) only $9 \%$ considered the tourism sector. Scott et al. (2008) explain this lack of research with the low awareness of climate change among tourism operators and little evidence of strategic planning in anticipation of future changes in climate. The tourism industry has proven its ability to cope with a range of shocks (e.g. the Asian Tsunami in 2004), yet we know very little about its capacity to prepare for future climate impacts (Scott and Becken 2010).

We have thus identified two gaps in the literature on adaptation: an incomplete (yet evolving) conceptualization of concrete barriers as tested in a case study, and a lack of attention paid to adaptation processes in the tourism sector. Following upon this research 
gap, the objective of this article is to analyze barriers appearing in the adaptation process in the tourism sector and to identify the most important among them. It specifically addresses the following questions:

i) What barriers hinder the adaptation process in the tourism sector and what is their importance?

ii) What policies, programs or measures are appropriate to overcome the identified barriers in the tourism sector?

We select Swiss Alpine tourism as a case study to analyze barriers to adaptation for three reasons: First, mountain areas are already more affected by climate change than other areas and thus mountain tourism already today is challenged to adapt to changing climate factors (Beniston 2005); second, there is a long history of research on the intensity and range of climate impacts already affecting the tourism sector in Switzerland (Bürki 1995; Elsasser et al. 1995; Abegg 1996; Meier 1998; Elsasser and Messerli 2001; Müller and Weber 2007, 2008; Abegg 2011); and third, tourism stakeholders already today address climate impacts in many regions of Switzerland (Matasci 2012). Our work contributes to adaptation research by providing a conceptual framework for the empirical analysis of barriers along the adaptation process, by offering a detailed view of such barriers in the tourism sector and by proposing solutions to overcome them. These results can be applied to other mountainous regions that are also highly dependent on tourism and might inform adaptation processes in other sectors as well.

\section{Research framework for analyzing barriers to adaptation}

Based on a literature review and on semi-structured interviews with tourism stakeholders carried out in a previous study (Matasci 2012), five families of barriers serve as reference for this case study: social feasibility, social acceptability, institutional feasibility, economic feasibility and technological feasibility. These families are similar to the determinants of adaptation given by Smit and Pilifosova (2001) and the barriers cited by Jantarasami et al. (2010) and by Jones (2010). In particular, we have designed our categories to be comprehensive in that they cover all aspects of planned adaptation, yet not mutually exclusive in that barriers specific to a case study may fall into more than one of these categories.

Barriers are phase-specific along the adaptation process and do not all arise at the same time (Fig. 1):

i) Barriers hindering social feasibility arise from the first phase of the adaptation process, when stakeholders must understand the need for adaptation. They include the difficulty of perceiving the changes already occurring in local climate or the difficulty of fully grasping the impacts of these changes. Stakeholders might not know their region well enough or might be unaware of the relevant scientific research or possible adaptation strategies and measures. In the planning and management phases, barriers hindering social feasibility include the difficulty of working together or involving other stakeholders, or simply the lack of social capital. A low level of social capital has been shown to prevent collective adaptation initiatives (Huang et al. 2011).

ii) Barriers hindering social acceptability also occur from the first phase of understanding the adaptation problem, when they prevent stakeholders who perceive the changes and recognize the impacts and could theoretically take action from actually doing so by choice. These barriers also play a crucial role in the planning and management phase of 


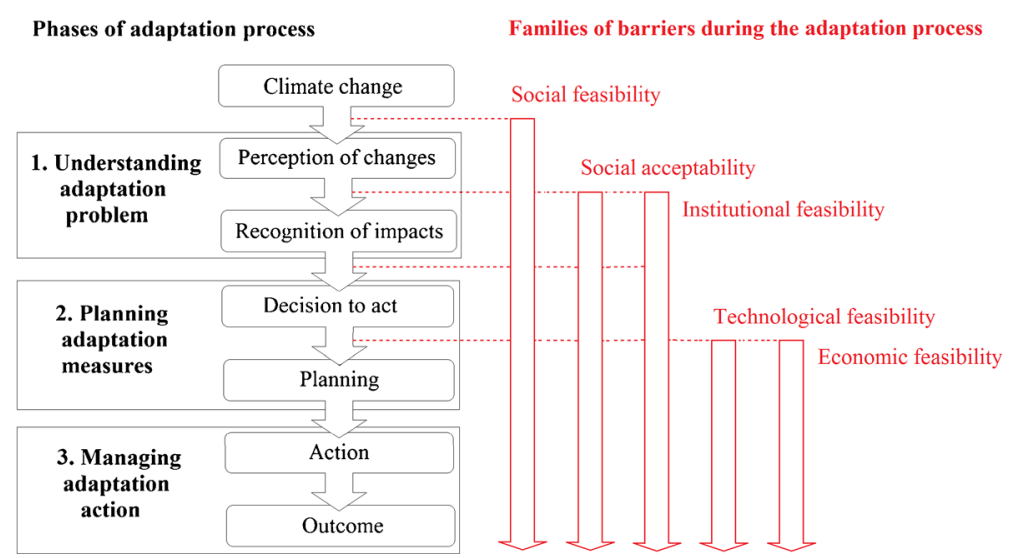

Fig. 1 Families of barriers and their presence along the climate change adaptation process

adaptation action; for example, this may occur when the population does not accept and blocks the chosen adaptation measures. Social acceptability is often strictly linked to intrapersonal, interpersonal and decision making factors that are, at their root, psychological (Gifford 2011). Stakeholders may resist adaptation measures when they attach greater priority to other, more day-to-day problems. They may also simply underestimate the exposure of their activities to the effects of climate change.

iii) Barriers hindering institutional feasibility are almost concurrent with barriers hindering social acceptability. They arise from rigid or weak institutions, blocked by existing policies and internal operating procedures. They also arise from the lack of political willingness to act at the various levels or by the lack of coordination and interaction in the tourism sector in the region.

iv) Barriers hindering economic feasibility come into play towards the end of the adaptation process, after stakeholders decided to act and are in the planning or the managing phase. These barriers typically take the form of insufficient funding or an unfavorable costbenefit ratio of planned measures.

v) Barriers hindering technological feasibility also intervene in the adaptation process during the planning and managing phase. Stakeholders may lack know-how about, for instance, protecting areas from natural hazards or building infrastructure on unstable soil.

This sequence of barriers shows that barriers involving social feasibility and social acceptability are critical in inhibiting the adaptation process due to the many forms they can take and because they arise early and affect every step of the adaptation process (Matasci 2012).

The barriers described above relate primarily to planned (i.e., proactive) adaptation; in other words, our research primarily provides a framework for understanding barriers to adaptation actions that occur when stakeholders incorporate relevant information about future climate change and plan measures to minimize the impact of those effects. Oftentimes, however, when climate-related events occur, stakeholders may not fully grasp the causes and consequences for their business but nonetheless they try to adapt ex post. In such cases of reactive adaptation, barriers are mainly related to institutional, economic and technological feasibility (Matasci 2012). 


\section{Data and methods}

In order to answer our two research questions in light of the framework presented above, we collected data through an online survey of stakeholders in Swiss tourism. The survey addressed the relative importance of barriers hindering adaptation processes. Moreover, it dug deeper into social acceptability barriers as they appear from the beginning of the adaptation process, measuring in particular the willingness to adapt of stakeholders. Finally, the survey was designed to reveal possible ways of overcoming barriers to adaptation, including contributions of decision makers and public policies.

Crafting the survey was preceded by a review of the literature on surveying, including Foddy (1993), discussions with stakeholders and researchers of the tourism sector, and interviews with stakeholders already adapting to climate change designed to gather information on barriers to adaptation and the theoretical process (Matasci 2012). The survey was also partially based on a previous survey on adaptive capacity of the tourism sector in the European Alps (Kruse et al. 2013).

Our survey contained 33 questions, of which 5 were related to barriers. The remaining 28 addressed climate change impacts and adaptation aspects in respondents' tourism regions and were used for other research. 6 questions allowed for open responses, which we coded and clustered. The survey was made available in German, French, Italian and English from November 2, 2011, to January 4, 2012. We invited by e-mail 8,416 stakeholders in the food and beverage serving services, passengers and transport services, accommodations, travel agencies, cultural services, or communal and cantonal tourism administrations to fill out the survey. This included almost all Swiss municipalities, cable car companies, tourism guides, tourism offices and hotels with a public e-mail address. 566 persons $(6.72 \%)$ filled out the questionnaire. We suspect that many non-participants were located in cities and the lower lying areas, where climate change is not yet seen as an issue.

\section{Results}

The online survey helps to answer our research questions. First, outcomes linked to the relative importance of the different families of barriers are presented in Section 4.1. Second, we examine barriers related to social acceptability in Section 4.2, with special emphasis on willingness to act of stakeholders. Finally, we show results on possible ways of overcoming identified barriers and the role of the public sector in Section 4.3.

\subsection{The importance of barriers}

The survey asked stakeholders to assess on a scale from 1 to 10 the importance of nine barriers to adaptation. Appendix 1 provides the precise formulation of these barriers and allocates them to the five families of barriers presented in Section 2. Average scores range from 4.76 (S.D 2.61) for the non-availability of technical solutions to 6.58 (S.D 2.62) for the lack of economic means and high costs of adaptation measures (Fig. 2). Only this economic constraint was seen as significantly $(p$-value $<0.05)$ more important than the lack of political willingness to act at the cantonal or national level (mean score $\mu=5.64$, S.D 2.44) (Student $t=4.22, p$-value $<0.001$ ). The scores for the other barriers allow a ranking but they are not significantly different.

An open question on the survey invited the stakeholders to indicate other possible barriers. They cited mainly the lack of long-term perspective ( 5 mentions) sometimes due 


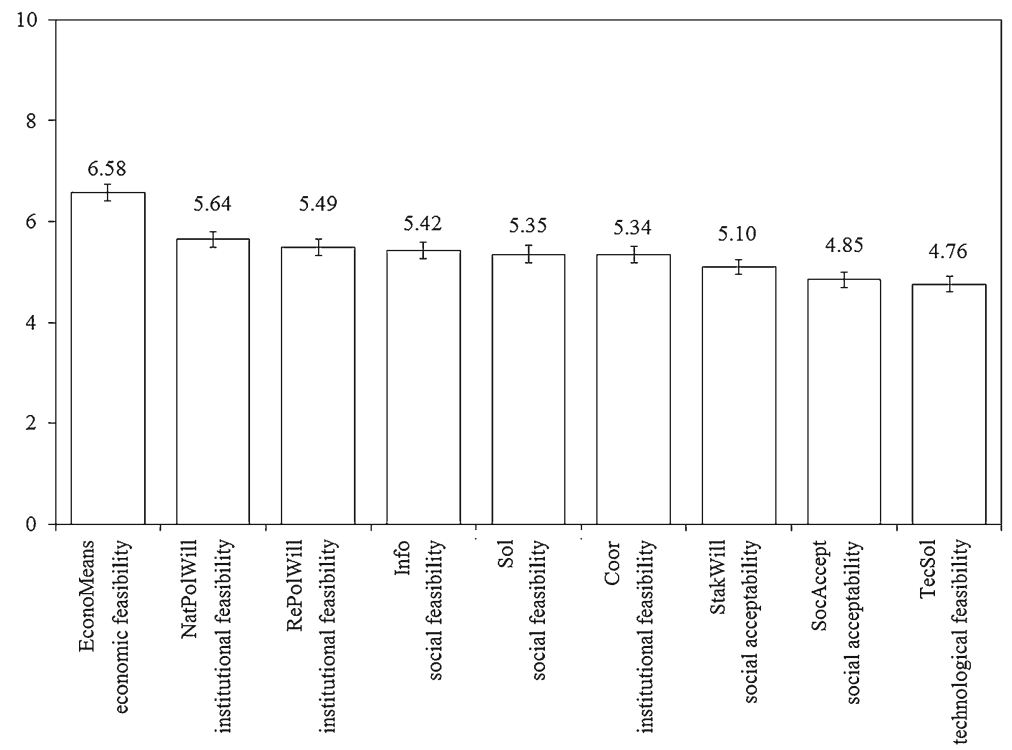

Fig. 2 Average score of importance attributed by the respondents to 9 barriers to adaption, on a scale from 1 to 10 (the meaning of the short names is provided in Appendix 1; vertical lines indicate mean standard errors)

to pressure of other stakeholders and to the need to obtain short-term results (1). Individual respondents also mentioned other (short-term) conditions to which a higher priority is given (such as e.g. the strong Swiss franc) ${ }^{1}$ (1), the lack of action at the international level (1) and the fear that changing the tourism offer would threaten jobs and incomes in the region (1).

The results show that stakeholders perceive economic constraints as the main barrier to adaptation. Indeed, even if a few resorts are highly profitable, most tourism areas and many operators only survive with public support (Gonseth 2008). At the other extreme, our results indicated that stakeholders are less worried that they may lack the technical know-how to adapt to climate change. This is likely due to the fact that many consequences of changing climatic conditions are related to natural hazards, which the inhabitants of mountain regions have learned to cope with over centuries. As a result, the inhabitants of these regions have a particular on-the-ground know-how that helps them adapt to the technical aspects of a changing climate (Hill et al. 2010).

\subsection{Social barriers: stakeholders' willingness to act}

A central component of social acceptability is stakeholders' willingness to act in order to adapt to the impacts of climate change. Their answers to the corresponding question in the online survey indicate a generally high willingness, with $38 \%$ of the respondents indicating that they would continue to act until a solution was found, even if this cost them substantial time and energy. A further $30 \%$ indicated that they would at least take part in a meeting if someone organized it. Fewer (14\%) seemed to be ready to start an adaptation process and

\footnotetext{
${ }^{1}$ Between September 2008 and time of our survey, the Swiss franc had appreciated by $30 \%$ relative to the Euro. This probably loomed large in the minds of several respondents.
} 
then stop it if a solution did clearly appear. Only $9 \%$ and $5 \%$ respectively did not see the need to act or would stop early in the process if this became too difficult. The remaining $4 \%$ gave other reasons. In our case study, therefore, we can claim with high conclusiveness that willingness to act among the Swiss tourism sector is not a barrier to adaptation action. To further test this claim, we carried out analyses of the differential willingness to act among the various types of survey respondents.

Willingness to act could be different between stakeholders in the private and public sector. This specific distinction was not tagged in the survey, so we allocated respondents working in the food and beverage serving services, passengers and transport services, and accommodation to the private sector. Stakeholders working in the cultural services, public administration, in public interest associations were allocated to the public sector. Respondents working in research, travel agencies or as mountain guides, in both private and public occupations or who did not specify their employment could not be allocated unambiguously and were therefore excluded from this private/public comparison. We could thus allocate 161 respondents to the private sector and 208 to the public sector. Among the latter, 164 could be allocated to the municipal or local level and 41 to the cantonal or national level. For 3 respondents the information was missing.

There exists no significant difference of willingness to act among private and public sector stakeholders (Table 1). Within the private sector, respondents with leadership responsibilities tended to be more willing to act (3.66) than subordinates (3.17). We attempted to establish these differences statistically by fitting a Generalized Linear Model (GLM) with Poisson errors to the scores, using as explanatory variables next to this level of responsibility the respondents' gender, age, geographical area, and sector of employment. However, this failed to reveal any significant explanatory variable for the willingness to take action for adaptation.

Similarly, we found no significant difference in the way in which stakeholders in the private and public sector perceive future impacts (over 2030-2050) of climate change on the tourism sector, nor its adaptive capacity. However, private stakeholders displayed a significantly higher perception of current problems caused by climate change in the region and of the regional vulnerability in relation to tourism. We found also differences among people working for the public sector respectively at the municipal/local and at the cantonal/national level. The latter perceive current and especially possible future problems for tourism in the region significantly higher than the ones working locally.

In summary, this section has shown that stakeholders of the tourism sector are willing to prepare for the effects of climate change. This finding is widely consistent throughout the various stakeholders, with no conclusive results showing which are more willing. That is a little surprising, considering that stakeholders working in the private sector are clearly more aware of current problems caused by climate changes in their region and its vulnerability than stakeholders working in the public sector. This perception is particularly low among stakeholders working in the local public sector. However, they share with all stakeholders the feeling that future problems are looming large, although less than stakeholders working in the cantonal or national public sector.

\subsection{Possible ways to overcome barriers and increase adaptive capacity}

The online survey invited stakeholders in an open question to indicate what, in their opinion, could help overcome the barriers presented in the introduction. 124 of the participants 
Table 1 Perceptions of exposure of the local tourism sector to climate change and willingness to act of different types of stakeholders

\begin{tabular}{|c|c|c|c|c|c|c|}
\hline Variables & & $\begin{array}{l}\text { Willingness } \\
\text { to } \operatorname{act}^{\mathrm{a}}\end{array}$ & $\begin{array}{l}\text { Current } \\
\text { problems }^{\mathrm{a}}\end{array}$ & $\begin{array}{l}\text { Future } \\
\text { problems }^{\mathrm{a}}\end{array}$ & $\begin{array}{l}\text { Adaptive } \\
\text { capacity }\end{array}$ & Vulnerability $^{\mathrm{b}}$ \\
\hline \multirow[t]{3}{*}{ Public $(N=208)$} & $\mu$ & 3.74 & 3.05 & 3.65 & 2.97 & 2.35 \\
\hline & S.D. & 1.29 & 1.12 & 1.09 & 0.89 & 0.73 \\
\hline & $\mathrm{Nb}$ & 201 & 200 & 193 & 195 & 194 \\
\hline \multirow[t]{4}{*}{ Private $(N=161)$} & $\mu$ & 3.62 & 3.39 & 3.83 & 3.09 & 2.60 \\
\hline & S.D. & 1.27 & 1.18 & 1.14 & 0.82 & 0.84 \\
\hline & $\mathrm{Nb}$ & 156 & 158 & 155 & 160 & 156 \\
\hline & $t$ & 0.89 & $-2.77 * *$ & -1.47 & -1.30 & $-2.93 * *$ \\
\hline \multirow{3}{*}{$\begin{array}{l}\text { Public municipal or } \\
\text { local }(N=164)\end{array}$} & $\mu$ & 3.66 & 2.93 & 3.51 & 2.96 & 2.30 \\
\hline & S.D. & 1.35 & 1.08 & 1.07 & 0.94 & 0.73 \\
\hline & $\mathrm{Nb}$ & 160 & 156 & 150 & 151 & 152 \\
\hline \multirow{4}{*}{$\begin{array}{l}\text { Public cantonal or } \\
\text { national }(N=41)\end{array}$} & $\mu$ & 4.03 & 3.41 & 4.08 & 3.00 & 2.49 \\
\hline & S.D. & 1.03 & 1.16 & 1.07 & 0.71 & 0.72 \\
\hline & $\mathrm{Nb}$ & 38 & 41 & 40 & 41 & 39 \\
\hline & $t$ & -1.84 & $-2.42^{*}$ & $-2.95 * *$ & -0.30 & -1.48 \\
\hline
\end{tabular}

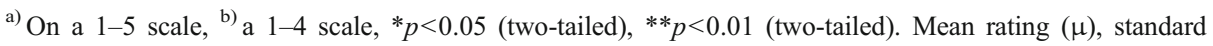
deviation (S.D.), number of responses $(\mathrm{Nb})$ and $t$-test comparisons $(t)$

answered this question and made different proposals. The most cited measure has to do with the lack of information among stakeholders about the regional impacts of climate change and possible adaptation measures and strategies. Stakeholders frequently mentioned the need for more and/or better information and communication about the consequences of climate change and about possible adaptation measures and support from the scientific community (cited 44 times), better cooperation among stakeholders and among political parties and higher public participation (19), and innovation and work on other conceptions of tourism and other target groups (12). Respondents also cited changes in mentality and a shift towards a more sustainable way of living and of thinking, in particular among policy makers (12), a higher willingness to act and adapt, in particular among decision makers and in the population (12), a higher awareness of the impacts and the consequences of climate change and of the importance of tourism in the region in the population and among stakeholders and decision makers (10). We also asked participants to present the principal way for decision makers and public policies to foster adaptation processes. Here too, the respondents mainly indicated that this could be done by providing continual, high-quality and honest written or visual information on climate change and on possible adaptation measures, both to stakeholders and to the population (cited 55 times). Other suggestions included the promotion of sustainable and long-term solutions (44), the provision of financial assistance (33) and the collaboration and discussion with stakeholders and scientists (18).

With regards to the specific kind of information that stakeholders thought they lacked, they indicated principally regional climate change scenarios (55\% of the 566 respondents), regional climate impact studies (39\%) and vulnerability assessments (38\%). What also emerged from the survey is that stakeholders obtain information primarily from newspapers ( $87 \%$ of the 566 respondents), television (70\%) and radio (56\%). Scientific publications 
(40\%), internal sources of information (36\%), invited scientists (12\%), external consultants $(10 \%)$ and others $(14 \%)$ follow.

Considering, more specifically, ways to overcome the lack of willingness to act, we asked stakeholders in the online survey to indicate in an open question what could make them change their opinion and their behavior. It appeared that they would be more willing to act if there were hmore cooperation among stakeholders (35\% of the 228 who answered the question), higher levels of leadership and direction from above (22\%), higher levels of general willingness to act and more political actions (21\%). $26 \%$ said that they were already engaged in adaptation measures. In looking at differences of answers in relation to stakeholders' willingness to act as defined in Appendix 2, our analyses reveal that lower willingness to act is correlated with higher probability of requesting top-down and political action (Table 2). Conversely, the higher the willingness to act, the higher the request of bottom-up action and of cooperation. More time and fewer financial constraints appeared to be frequently cited aspects for low levels of willingness to act. Some of the persons who did not see the need to act indicated that nothing could make them take action, while others indicated that they were already acting.

Finally, in order to define which elements could influence willingness to take adaptation action, we looked at correlations between stakeholders' answers to this question and their answers to questions about perceived present and future potential impacts affecting the region, perceived adaptive capacity and perceived vulnerability (Fig. 3). We found a small positive but highly significant Pearson correlation between willingness to act and perception of both present and future potential impacts. The relationship with perceived adaptive capacity is bell-shaped: willingness to act is very low when perceived adaptive capacity is low, but also when adaptive capacity is perceived as very high. Possible explanations for this interesting finding will be explored in the next section. The

Table 2 What could make stakeholders more willing to act to adapt to climate change?

\begin{tabular}{lllllc}
\hline Level of willingness to act & $\begin{array}{l}\text { None } \\
(N=22)\end{array}$ & $\begin{array}{l}\text { Level } 2 \\
(N=7)\end{array}$ & $\begin{array}{l}\text { Level 3 } \\
(N=67)\end{array}$ & $\begin{array}{l}\text { Level } 4 \\
(N=22)\end{array}$ & $\begin{array}{l}\text { Very high } \\
(N=90)\end{array}$ \\
\hline I wouldn't act anyway & $5(23 \%)$ & 0 & $3(4 \%)$ & 0 & 0 \\
More time & 0 & $1(14 \%)$ & $6(9 \%)$ & 0 & $1(1 \%)$ \\
More financial means & 0 & $1(14 \%)$ & $1(1 \%)$ & $2(9 \%)$ & $1(1 \%)$ \\
Clear solutions & 0 & 0 & $5(7 \%)$ & $3(14 \%)$ & $4(4 \%)$ \\
More/better information & 0 & 0 & $8(12 \%)$ & $5(23 \%)$ & $3(3 \%)$ \\
Evidence of impacts & $3(14 \%)$ & 0 & $12(18 \%)$ & $1(5 \%)$ & $12(13 \%)$ \\
An impact on my wellbeing & $1(5 \%)$ & $1(14 \%)$ & $6(9 \%)$ & $2(9 \%)$ & $12(13 \%)$ \\
Power of action & $4(18 \%)$ & $2(29 \%)$ & $11(16 \%)$ & $3(14 \%)$ & $2(2 \%)$ \\
Political action & $4(18 \%)$ & $2(29 \%)$ & $12(18 \%)$ & $4(18 \%)$ & $12(13 \%)$ \\
Direction & $2(9 \%)$ & $1(14 \%)$ & $19(28 \%)$ & $6(27 \%)$ & $8(9 \%)$ \\
Cooperation & $1(5 \%)$ & $2(29 \%)$ & $15(22 \%)$ & $6(27 \%)$ & $33(37 \%)$ \\
General willingness to act & $2(9 \%)$ & $1(14 \%)$ & $12(18 \%)$ & $4(18 \%)$ & $16(18 \%)$ \\
I already act & $5(23 \%)$ & $1(14 \%)$ & $6(9 \%)$ & $3(14 \%)$ & $30(33 \%)$ \\
\hline
\end{tabular}

Number of answers and percentage for different categories of responses to the open question "What could make you change your ideas and your behavior?", distinguishing stakeholders by their level of willingness to act as defined in Appendix $2(N=208)$ 


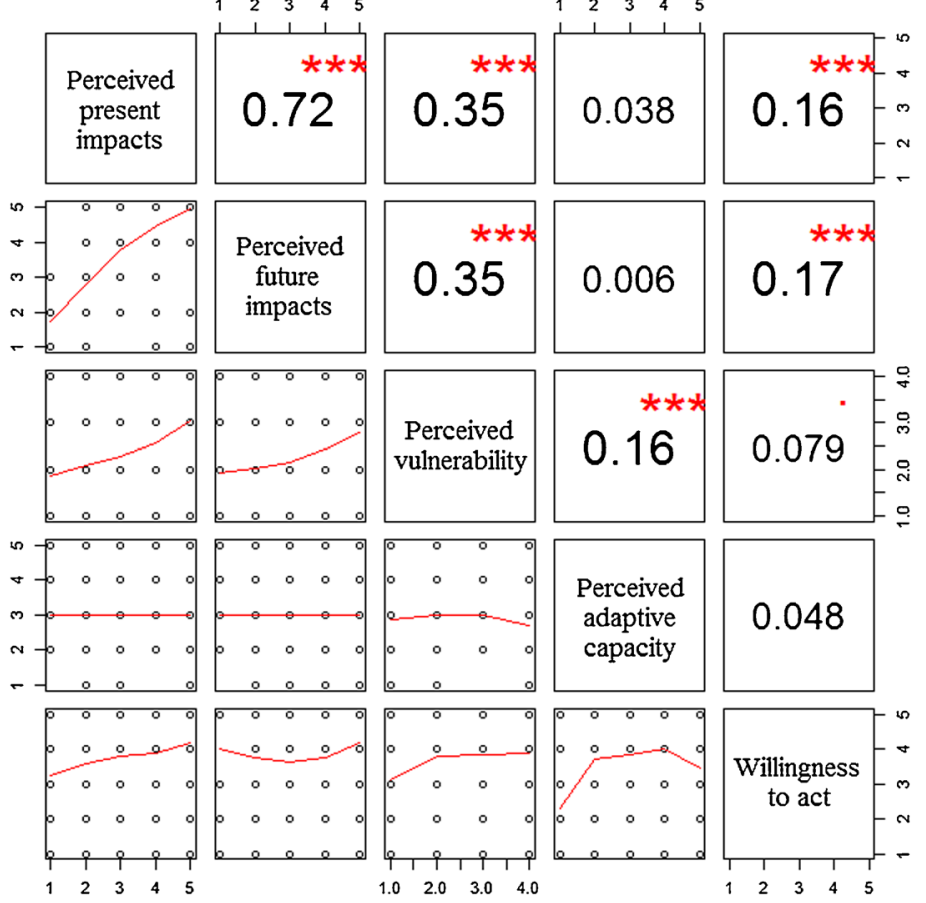

Fig. 3 Correlation between willingness to act and perceptions of the need to act (Scatter plots are shown below the diagonal and Pearson's correlation coefficients above it. $(N=481)$ (*significant at $5 \%$; *** significant at $0.1 \%)$ )

relationship with perceived vulnerability is monotonically increasing but flattens out at middle vulnerability perception.

In summary, this section has shown that the lack of quality information about climate change and its local effects is a major brake on stakeholders' personal and collective adaptation action. The better they are informed about present and future impacts for tourism, the more likely they are to act, unless they are convinced that the sector has a high adaptive capacity. Passivity may also result from a sense of defeatism: stakeholders who consider the sector poorly adaptable are also reluctant to act. When a stakeholder assesses the tourism sector as poorly or, on the contrary, highly adaptable, she is assessing the willingness to act of the other stakeholders. This comparison with others is crucial. Not surprisingly, many respondents noted that they considered leadership and incentives for cooperation as conditions for their own actions. Interestingly, even if stakeholders consider economic feasibility as the most important barrier to the adaptation process, they mention few ways to overcome them.

\section{Discussion and Conclusion}

As Matasci (2012) and Moser and Ekstrom (2010) have shown, barriers arise at all phases of the adaptation process. They concluded that a certain level of pressure had to be reached for stakeholders to move from one phase to the next, for example, from the recognition of the 


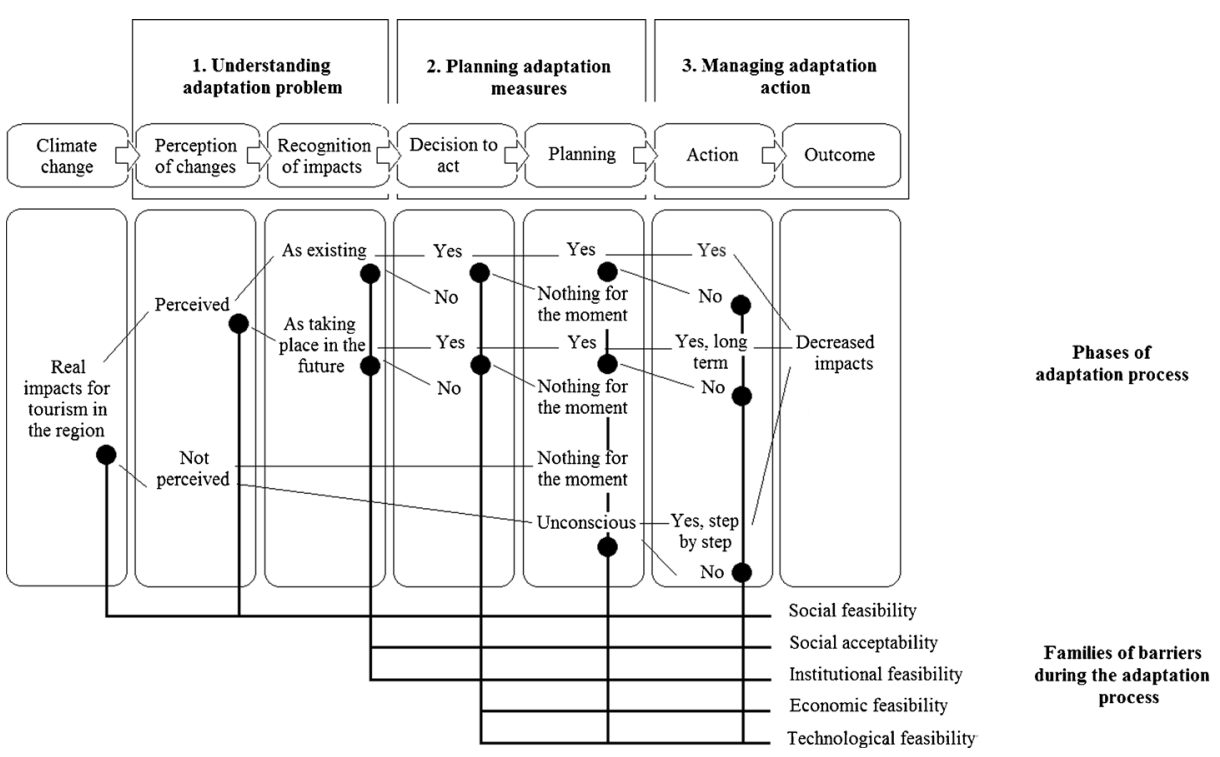

Fig. 4 The adaptation process and how barriers slow it down (The upper boxes describe possible processes leading to adaptation and reduced impacts. Marked as dots and described in the lower part of the figure are the five families of barriers that can intervene in the process and their temporal development)

impacts to the decision to act, from the decision to act to planning and from planning to actual action (Fig. 4). For example, lack of information and communication can hinder the perception of changes and the recognition of climate change impacts. Alternatively, tourism stakeholders may perceive the impacts of climate change for their region, yet they postpone action until they feel that their business or wellbeing is threatened. In the same way, once the decision to act has been made, if there is not enough information on the impacts and the possible adaptation options, if stakeholders distrust information sources or if stakeholders are unable to collaborate and communicate, then the planning and the action phases will never be reached. Starting from the planning phase, the lack of financial resources begins to represent a serious threat to the advancement of the process.

Our stakeholder survey showed that all types of barriers are generally perceived as important, particularly economic and institutional feasibility barriers. This can be explained by the fact that even if few resorts are highly profitable, most tourism areas and many operators in the country only survive with public support (Gonseth 2008). On the other hand, the respondents assigned low importance to technical barriers, which can be explained by the long tradition in the Swiss mountainous regions of implementing technical solutions to natural hazards (Hill et al. 2010). Barriers related to social acceptability, both of the general population and of stakeholders, do not seem to particularly threaten the process of adaptation in Switzerland. Swiss inhabitants are aware of the impacts of climate change and of the consequences for the tourism sector and they believe that adaptive action should be taken (Matasci 2012). This is particularly true in regions where adaptation is most needed: their population is often very closely linked to tourism, which is in turn the backbone of the local economy. Awareness of the changing climate is, however, a relatively recent phenomenon (Hill et al. 2010; Matasci 2012). Previously, tourism operators showed low awareness of climate change (Scott et al. 2008). The stakeholders' willingness to take action in order to adapt appeared to be rather high in all parts of the tourism sector and related organizations. 
Our results can be contrasted with those of Nielsen and Reenberg (2010) and Adger et al. (2009), who suggest differences in willingness to take action due to scale and agency. We could not find any systematic dependency of adaptation decisions on social and individual characteristics. This could be due to the importance of the tourism sector in the socioeconomic and political structure of many parts of Switzerland.

When respondents showed low willingness to take action, this could be linked to a preference for mitigation over adaptation, as revealed by their emphasis on options such as sustainable measures and long-term solutions. Reluctance to change habits and mistrust of information provided might be other causes for low willingness to act, as found also by Gifford (2011) and Lorenzoni et al. (2007).

One of the possible reasons for insufficient adaptation, which was not included in our survey but came up in some earlier interviews, is the difficulty of coordinating two neighboring municipalities or ski-area operators. Adaptation options are often local public goods, benefiting not only the municipality or the company that invests in order to adjust to the impacts but also its neighbor. Stakeholders are then confronted with issues of collective action, allocation of costs, free riding and trust. Results are very similar to those found by Lorenzoni et al. (2007) concerning barriers to engaging with climate change perceived among UK inhabitants.

Similarly, we found that stakeholders very much consider what other stakeholders do to adapt, to the point that many call for top-down leadership and coordination before they accept to act themselves, as in Amundsen et al. (2010) and Gifford (2011). On the contrary, some decide not to act because they consider tourism to have high adaptive capacity, apparently independently of their own contribution. It would be difficult to alter the beliefs of these people who may be either considering their role too modestly, underestimating tourism's exposure or simply free-riding. Those who wait to act until they are invited to do so in a coordinated fashion could be nudged into action by just such top-down guidance and coordination.

We have identified the pathways through which policy solutions can intervene in the most pertinent adaptation barriers. In our case study, these were barriers related to social feasibility and economic concerns. The stakeholders themselves emphasized social feasibility, which the public sector could improve with more and better information on both regional impacts and adaptation options. Respondents may have called for this measure because it is easily applicable, more so than finding direct ways of overcoming economic hurdles. Many stakeholders mistrust the information they get. Because stakeholders primarily obtain their scientific information through second-hand channels like newspapers, television, and radio, a significant barrier to adaptation can be minimized by facilitating the channels through which scientists can more directly transmit their research to various economic sectors affected by their findings. Targeted and better information could be a way to increase political and stakeholders' willingness to act and to encourage coordination and interaction in the tourism sector in the region. Willingness to act in order to adapt is highly correlated with perception of present and future regional impacts.

Another pathway through which the public sector could act, as it appeared from the online survey, is the importance of including all the concerned stakeholders from the beginning in the adaptation process. Fundamental components of the success of an adaptation process are therefore participative processes, transparent information and effective communication among stakeholders, as also collaborative work and a common strategy.

All this should not mask the importance of economic barriers. Clearly, here as well the public sector is called for with, for example, financial support in the form of subsidies and interest-free loans. These instruments exist, but they could be enhanced, focused on adaptation or otherwise improved. 
It would be desirable to repeat this study with a larger sample, making sure that stakeholders most sensitive to the topic do not self-select. Furthermore, it should be tested that their answers are congruent with their actual behavior (Foddy 1993; Gifford 2011). In particular, future studies should make sure to distinguish those who declare themselves willing to take adaptive action and actually do so from those who just report willingness with no consequent evidence of that willingness. If such research is repeated in another regional context, it might be necessary to consider also barriers related to equity (Smit and Pilifosova 2001), which we ignored under the plausible assumption that it is not an issue in Switzerland. Depending on the context, another family of barriers that might have been considered includes environmental feasibility (e.g. ecosystem thresholds and resilience, geographic and geological limitations, limits on natural resources). We considered these barriers as limits that cannot be overcome by any direct means. Finally, we did not consider the natural, fundamental and irreducible uncertainty related to future demographic, socioeconomic, technologic, environmental and climatic conditions (Dessai et al. 2009; Huang et al. 2011). Natural uncertainty also cannot be overcome directly, differently from epistemic (systematic) one, even though it can still be an important factor interfering with adaptation processes. ${ }^{2}$

Acknowledgments The authors gratefully acknowledge the support of the Swiss Federal Office for the Environment (FOEN) as well as of the Swiss National Centre of Competence in Research on Climate (NCCR Climate) which is funded by the Swiss National Science Foundation (SNF). All their gratitude also goes out to the various people who took part in the surveys.

Open Access This article is distributed under the terms of the Creative Commons Attribution License which permits any use, distribution, and reproduction in any medium, provided the original author(s) and the source are credited.

\section{Appendices}

\section{Appendix 1}

This is the question asked of tourism stakeholders in the survey (the short names for barriers and the family to which they belong were added):

Which do you think are the most important obstacles to the implementation of measures and strategies that help facing climate change in the tourism sector in your region? $(1=$ not important; $10=$ very important)

i. The resistance and blocking of the local population to the implementation of adaptation measures (SocAccept, social acceptability)

ii. The lack of political willingness to act in the region (RePolWill, institutional feasibility)

iii. The lack of political willingness to act at the cantonal or national level (NatPolWill, institutional feasibility)

iv. The lack of willingness to act of people working in the tourism sector in the region (StakWill, social acceptability)

v. The lack of coordination and interaction in the tourism sector in the region (Coor, institutional feasibility)

\footnotetext{
${ }^{2}$ Even if, as nicely stated by Dessai et al. (2009), successful adaptation can be developed in the face of irreducible uncertainty by selecting options that are sufficiently robust across alternative futures.
} 
vi. The low economic means at disposal and the costs of the adaptation measures (EconoMeans, economic feasibility)

vii. The non-availability of technological solutions (TecSol, technological feasibility)

viii. The lack of information about the regional impacts of climate change and possible adaptation measures and strategies among stakeholders (Info, social feasibility)

ix. The lack of feasible solutions (Sol, social feasibility)

\section{Appendix 2}

We measured willingness to act by the energy and time stakeholders invested in the process. In one of the questions of the online survey, we assessed to what extent they would be willing to initiate and carry forward an adaptation process: the more they declared themselves to be willing to carry the process regardless of the time and energy this requires, the more we considered them willing to adapt. We proposed five levels of engagement, attributing to them a score between 1 and 5 . These are (from the weakest to the strongest):

Level 1 I do not see the need to act; I would continue my business as usual;

Level 2 I would start searching for information but would stop if this becomes too difficult;

Level 3 I would not be the organizer of a meeting, but if someone else were gathering people in order to think about possible solutions, I would join for at least one meeting;

Level 4 I would collect and review information and I would then start planning possible solutions and eventually contact people; but I would stop if a possible solution did not clearly appear;

Level 5 I would try to organize other concerned people in my region to find possible solutions until something is found; I would do so even if it were to take much time and energy and until a solution were found.

\section{References}

Abegg B (1996) Klimaänderung und Tourismus. Vdf Hochschulverlag, Zürich

Abegg B (2011) Tourismus im Klimawandel - ein Hintergrundbericht der CIPRA. Compact. CIPRA, Schaan Adger WN, Barnett J (2009) Four reasons for concern about adaptation to climate change. Environ Plan A 12:2800-2805

Adger WN, Dessai S et al (2009) Are there social limits to adaptation to climate change? Clim Change 93:335-354

Amundsen H, Berglund F et al (2010) Overcoming barriers to climate change adaptation a question of multilevel governance? Environ Plan C-Gov Policy 28:276-289

Beniston M (2005) Mountain climates and climatic change: an overview of processes focusing on the European Alps. Pure Appl Geophys 162:1587-1606

Berrang-Ford L, Ford JD, Paterson J (2011) Are we adapting to climate change? Global Environ Change 21:25-33

Bürki R (1995) Klimaänderung, Schneearmut und Wintertourismus im Obertoggenburg. Forschungsstelle für Wirtschaftsgeographie und Raumplanung (FWR-HSG), St. Gallen

Dessai S, Hulme M et al (2009) Climate prediction: a limit to adaptation? In: Adger WN, Lorenzoni I, O’Brien KL (eds) Adapting to climate change - thresholds, values, governance. Cambridge University Press, Cambridge

Dupuis J, Knoepfel P (2011) Barriers to the implementation of adaptation policies to climate change: the case of Switzerland. Swiss Polit Sci Rev 17:188-219

Ekstrom JA, Moser SC et al (2011) Barriers to climate change adaptation: a diagnostic framework-final project report. Lawrence Berkeley National Laboratory, Berkeley 
Elsasser H, Messerli P (2001) The vulnerability of the snow industry in the Swiss Alps. Mount Res Dev $21: 335-339$

Elsasser H, Abegg B et al (1995) Winter ohne Schnee? Klimaänderung und Tourismus im Alpenraum. Institut für Raumplanung und Ländliche Neuordnung an der Universität für Bodenkultur (IRUB), Wien

Foddy W (1993) Constructing questions for interviews and questionnaires: theory and practice in social research. Victoria Cambridge University Press, Victoria

Ford JD, Berrang-Ford L, Paterson J (2011) A systematic review of observed climate change adaptation in developed nations. Clim Change 106:327-336

Gifford R (2011) The dragons of inaction: psychological barriers that limit climate change mitigation and adaptation. Am Psychol 66:290-302

Gonseth C (2008) Adapting ski area operations to a warmer climate in the Swiss Alps through snowmaking investments and efficiency improvements. Dissertation, École Polytechnique Fédérale de Lausanne (EPFL), Lausanne

Gössling S, Hall CM (eds) (2006) Tourism and global environmental change. Routledge, London

Grothmann T, Patt A (2005) Adaptive capacity and human cognition: the process of individual adaptation to climate change. Global Environ Change 15:199-213

Hall CM, Higham J (eds) (2005) Tourism, recreation and climate change: international perspectives. Channel View Publications, Clevedon

Hill M, Wallner A, Furtado J (2010) Reducing vulnerability to climate change in the Swiss Alps: a study of adaptive planning. Clim Pol 10:70-86

Huang CR, Vaneckova P et al (2011) Constraints and barriers to public health adaptation to climate change - a review of the literature. Am J Prev Med 40:183-190

IPCC (2007) In: Core Writing Team, Pachauri RK, Reisinger A (eds) Climate change 2007: synthesis report. Contribution of working groups I, II and III to the fourth assessment report of the Intergovernmental Panel on Climate Change. IPCC, Geneva

Jantarasami LC, Lawler JJ et al (2010) Institutional barriers to climate change adaptation in US national parks and forests. Ecol Soc 15

Jones L (2010) Overcoming social barriers to adaptation. Overseas Development Institute, London

Jones L, Boyd E (2011) Exploring social barriers to adaptation: insights from Western Nepal. Global Environ Change 21:1262-1274

Kruse S, Stiffler M, Baumgartner D, Pütz M (2013) Vulnerability and adaptation to climate change in the Alpine space: a case study on the adaptive capacity of the tourism sector. In: Schmidt-Thomé P, Greiving S (eds) European climate vulnerabilities and adaptation: a spatial planning perspective. Wiley, Chichester, pp 273-287

Lata S, Nunn P (2012) Misperceptions of climate-change risk as barriers to climate-change adaptation: a case study from the Rewa Delta, Fiji. Clim Change 110:169-186

Lorenzoni I, Nicholson-Cole S et al (2007) Barriers perceived to engaging with climate change among the UK public and their policy implications. Global Environ Change 17:445-459

Matasci C (2012) Swiss tourism in the age of climate change - vulnerability, adaptive capacity and barriers to adaptation. Dissertation, École Polytechnique Fédérale de Lausanne (EPFL), Lausanne

Measham TG, Preston BL et al (2011) Adapting to climate change through local municipal planning: barriers and challenges. Mitig Adapt Strateg Glob Change 16:889-909

Meier R (1998) Sozioökonomische Aspekte von Klimaänderungen und Naturkatastrophen in der Schweiz. Schlussbericht des Nationales Forschungsprogramm "Klimaänderungen und Naturkatastrophen" (NFP 31). Vdf Hochschulverlag AG an der ETH Zürich, Zürich

Moser SC, Ekstrom JA (2010) A framework to diagnose barriers to climate change adaptation. In: Proceedings of the National Academy of Sciences of the United States of America, 2010

Müller H, Weber F (2007) Klimaänderung und Tourismus: Szenarienanalyse für das Berner Oberland 2030. Forschungsinstitut für Freizeit und Tourismus (FIF) der Universität Bern, Bern

Müller H, Weber F (2008) 2030: le tourisme suisse face aux changements climatiques. Suisse Tourisme. Forschungsinstitut für Freizeit und Tourismus (FIF) der Universität Bern, Bern

Nielsen JO, Reenberg A (2010) Cultural barriers to climate change adaptation: a case study from Northem Burkina Faso. Global Environ Change 20:142-152

Scott D, Becken S (2010) Adapting to climate change and climate policy: progress, problems and potentials. J Sust Tour 18:283-295

Scott D, de Freitas C, Matzarakis A (2008) Adaptation in the tourism and recreation sector. In: Ebi K, Burton I, McGregor G (eds) Biometeorology for adaptation to climate variability and change. Springer, Dordrecht, pp 171-194

Scott DJ, Lemieux CJ, Malone L (2011) Climate services to support sustainable tourism and adaptation to climate change. Clim Res 47:111-122 
Scott D, Gössling S, Hall CM (2012) International tourism and climate change. Clim Change 3:213-232

Smit B, Pilifosova O (2001) Adaptation to climate change in the context of sustainable development and equity. In: McCarthy JJ, Canziani OF, Leary NA, Dokken DJ, White KS (eds) Climate change 2001: impacts, adaptation and vulnerability. Contribution of working group II to the third assessment report of the Intergovernmental Panel on Climate Change (IPCC). Cambridge University Press, Cambridge

Smith MS, Horrocks L, Harvey A, Hamilton C (2011) Rethinking adaptation for a $4^{\circ} \mathrm{C}$ world. Phil Trans R Soc A 369:196-216

Storbjörk S (2010) 'It takes more to get a ship to change course': barriers for organizational learning and local climate adaptation in Sweden. J Environ Policy Plan 12:235-254 